Check for updates

Cite this: RSC Adv., 2019, 9, 11922

Received 5th February 2019

Accepted 30th March 2019

DOI: 10.1039/c9ra00956f

rsc.li/rsc-advances

\section{Improvement of electric field-induced strain and energy storage density properties in lead-free BNKT-based ceramics modified by BFT doping}

\author{
Pharatree Jaita, ${ }^{\text {ab }}$ Ratabongkot Sanjoom, ${ }^{c}$ Narumon Lertcumfu ${ }^{a}$ \\ and Gobwute Rujijanagul (DD *ab
}

In this research, the effects of $\mathrm{Ba}\left(\mathrm{Fe}_{0.5} \mathrm{Ta}_{0.5}\right) \mathrm{O}_{3}$ (BFT) additive on the phase evolution, the dielectric, ferroelectric, piezoelectric, electric field-induced strain responses, and energy storage density of the $\mathrm{Bi}_{0.5}\left(\mathrm{Na}_{0.80} \mathrm{~K}_{0.20}\right)_{0.5} \mathrm{TiO}_{3}-0.03\left(\mathrm{Ba}_{0.70} \mathrm{Sr}_{0.03}\right) \mathrm{TiO}_{3}$ (BNKT-0.03BSrT) ceramics have been systematically investigated. The ceramics have been prepared by a solid-state reaction method accompanied by two calcination steps. X-ray diffraction indicates that all ceramics coexist between rhombohedral and tetragonal phases, where the tetragonal phase becomes dominant at higher BFT contents. The addition of BFT also promotes the diffuse phase transition in this system. A significant enhancement of electric field-induced strain response $\left(S_{\max }=0.42 \%\right.$ and $\left.d_{33}^{*}=840 \mathrm{pm} \mathrm{V}^{-1}\right)$ is noted for the $x=0.01$ ceramic. Furthermore, the giant electrostrictive coefficient $\left(Q_{33}=0.0404 \mathrm{~m}^{4} \mathrm{C}^{-2}\right)$ with a giant normalized electrostrictive coefficient $\left(Q_{33} / E=8.08 \times 10^{-9} \mathrm{~m}^{5} \mathrm{C}^{-2} \mathrm{~V}^{-1}\right)$ are also observed for this composition $(x=$ 0.01). In addition, the $x=0.03$ ceramic shows good energy storage properties, i.e. it has a high energy storage density $\left(W=0.65 \mathrm{~J} \mathrm{~cm}^{-3}\right.$ (a $\left.120{ }^{\circ} \mathrm{C}\right)$ with very high normalized storage energy density $(W / E=$ $0.13 \mu \mathrm{C} \mathrm{mm}{ }^{-2}$ ), and good energy storage efficiency $\left(\eta=90.4 \%\right.$ (a $120^{\circ} \mathrm{C}$ ). Overall, these results indicate that these ceramics are one of the promising candidate piezoelectric materials for further development for actuator and high electric power pulse energy storage applications.

\section{Introduction}

For actuator applications, electrostriction is an important property which describes how the material deforms when polarization develops inside. ${ }^{1}$ Electrostriction occurs in materials with either centro or noncentrosymmetric crystal structures, and is caused by a slight displacement of ions (or complexes) in the crystal lattice when the material is subjected to an applied field. ${ }^{2}$ In the case of electrostriction, the fieldinduced strain $(S)$ can be simply related to the polarization $(P)$ by: $S=Q_{33} P^{2}$, where $Q_{33}$ represents the electrostrctive coefficient. ${ }^{2-5}$ A large $Q_{33}$ value of $\sim 0.020 \mathrm{~m}^{4} \mathrm{C}^{-2}$ with a good hysteresis-free electrostrictive strain $(\sim 0.1 \%)$ can be observed in some lead-based relaxor ferroelectrics, such as $\mathrm{Pb}\left(\mathrm{Mg}_{1 / 3} \mathrm{Nb}_{2 / 3}\right)$ $\mathrm{O}_{3}$ (PMN), ${ }^{3}$ which is known as an important electrostrictive material. ${ }^{5}$ However, because of the concern for environmental problems that lead-based materials pose, the development of

\footnotetext{
${ }^{a}$ Department of Physics and Materials Science, Faculty of Science, Chiang Mai University, Chiang Mai 50200, Thailand. E-mail: rujijanagul@yahoo.com

${ }^{b}$ Science and Technology Research Institute, Chiang Mai University, Chiang Mai 50200, Thailand

'Department of Applied Science and Biotechnology, Faculty of Agro-Industrial Technology, Rajamangala University of Technology Tawan-ok Chanthaburi Campus, Chanthaburi 22210, Thailand
}

lead-free electrostrictive piezoelectric materials has been urgent in recent years. ${ }^{3,5,6}$

Among many lead-free piezoelectric materials, $\left(\mathrm{Bi}_{0.5} \mathrm{Na}_{0.5}\right)$ $\mathrm{TiO}_{3}$-based (BNT) ceramic is an interesting material due to its relatively excellent electrical properties, especially for ferroelectric and piezoelectric properties ${ }^{7}$ i.e. high electric energy densities $^{8}$ and ultra-high strain under a high electric field $(\geq 50$ $\left.\mathrm{kV} \mathrm{cm}{ }^{-1}\right) .{ }^{9}$ However, the large coercive electric field $\left(E_{\mathrm{c}}=7.3 \mathrm{kV}\right.$ $\mathrm{mm}^{-1}$ ) and high electrical conductivity made it difficult to be polarized during the poling process, which often leads to undesirable piezoelectricity $\left(d_{33}=73-95 \mathrm{pC} \mathrm{N}^{-1}\right)$ and limited its applications. ${ }^{10}$ In order to reduce the $E_{\mathrm{c}}$ and/or improve the electrical properties, researches on composition-modified BNT systems have been conducted such as BNT-BT, ${ }^{11,12}$ BNT-ST, ${ }^{13}$ BNT-BZT-SBT, ${ }^{14}$ and BNT-BKT. ${ }^{15,16}$ Ullah et al. ${ }^{17}$ studied the effect of $\left(\mathrm{Ba}_{0.70} \mathrm{Sr}_{0.30}\right) \mathrm{TiO}_{3}$ (BST) on the structure and electrical properties of the $\mathrm{Bi}_{0.5}\left(\mathrm{Na}_{0.40} \mathrm{~K}_{0.10}\right) \mathrm{TiO}_{3}$ (BNKT) ceramic. They reported that this ceramic exhibited good electrical properties i.e. the ceramics presented high piezoelectric coefficient $\left(d_{33}=\right.$ $223 \mathrm{pC} \mathrm{N}^{-1}$ ) with dielectric loss $(\tan \delta)$ of $3 \%$ at $1 \mathrm{kHz}$. They also found that the La additive interrupted the $P-E$ hysteresis loops of the BNKT-BST ceramics, which lead to a reduction in $P_{\mathrm{r}}$ and $E_{\mathrm{c}}$ values. ${ }^{18}$ However, the destabilization of the ferroelectric order corresponded to a significant increase of the unipolar strain which showed the highest value of $\sim 0.39 \%$ and 
corresponding a normalized strain $\left(d_{33}^{*}=S_{\max } / E_{\max }\right)$ of $650 \mathrm{pm}$ $\mathrm{V}^{-1} .^{18}$ Therefore, research on modified BNKT-BST ceramics is an important topic in order to develop lead-free ceramics with high electrical properties.

An interesting work for electrostrictive materials was performed by Zhang et al. ${ }^{19}$ who provided a research direction to develop the $(1-x)\left[0.94 \mathrm{Bi}_{0.5} \mathrm{Na}_{0.5} \mathrm{TiO}_{3}-0.06 \mathrm{BaTiO}_{3}\right]-x \mathrm{~K}_{0.5} \mathrm{Na}_{0.5}{ }^{-}$ $\mathrm{NbO}_{3}$ system with a large electrostrictive coefficient $\left(Q_{33} \sim\right.$ 0.021-0.027 $\left.\mathrm{m}^{4} \mathrm{C}^{-2}\right)$ and the maximum strain $\left(S_{\max } \sim 0.12-\right.$ $0.30 \%$ ) values simultaneously. Beside Zhang et al.'s work, a large electrostrictive effect with $Q_{11}=0.0297 \mathrm{~m}^{4} \mathrm{C}^{-2}$ was also obtained by Shi et al. ${ }^{20}$ in the $(0.94-x)\left(\mathrm{Bi}_{0.5} \mathrm{Na}_{0.5}\right) \mathrm{TiO}_{3}-$ $0.06 \mathrm{BaTiO}_{3}-x\left(\mathrm{Sr}_{0.7} \mathrm{Bi}_{0.2} \square_{0.1}\right) \mathrm{TiO}_{3}$ system, in which its $Q_{11}$ exhibits a high temperature stability between ambient temperature to $180{ }^{\circ} \mathrm{C}^{20}$ Moreover, a high strain $\left(S_{\max } \sim 0.45 \%\right)$ was also found in the $\left(\mathrm{Bi}_{0.5} \mathrm{Na}_{0.5}\right) \mathrm{TiO}_{3}-\mathrm{BaTiO}_{3}-\left(\mathrm{K}_{0.5} \mathrm{Na}_{0.5}\right) \mathrm{NbO}_{3}$ or BNT-BT-KNN ceramic by Zhang et al., ${ }^{21}$ which is even higher than the strain value obtained in the lead ferroelectric $\mathrm{Pb}(\mathrm{Zr}, \mathrm{Ti})$ $\mathrm{O}_{3}$ ceramic. However, due to the phase evolution in BNT-based materials, large strain hysteresis larger than $60 \%$ can be observed inherently, which restricts the practicability use as electrostrictive materials. ${ }^{4}$ Thus research on the reduction of the strain hysteresis for the lead-free materials such as BNKTBST based materials is an interesting issue for the lead-free actuators.

Recently, many authors have suggested that the iron oxide such as $\mathrm{Fe}_{2} \mathrm{O}_{3}$ additive can improve the piezoelectric and magnetic properties of some lead-free piezoelectric ceramics. ${ }^{22,23}$ In the case of piezoelectric properties, Jaita et al. ${ }^{23}$ reported that the $\mathrm{Fe}_{2} \mathrm{O}_{3}$ additive can enhance the electric fieldinduced strain of BNKT-based ceramics. However, the electrostriction and electric field-induced strain properties of lead-free piezoelectric materials such as BNT-based ceramics doped with complex perovskite materials containing $\mathrm{Fe}$ have not been widely investigated. For the Fe-containing complex perovskite material, i.e. barium iron tantalate $\left(\mathrm{BaFe}_{0.5} \mathrm{Ta}_{0.5} \mathrm{O}_{3} ; \mathrm{BFT}\right)$ is interesting because it exhibits a giant dielectric material which has attracted great attention due to its very high dielectric constant $\left(\varepsilon_{\mathrm{r}} \sim 1.9 \times 10^{5}\right.$ at $550{ }^{\circ} \mathrm{C}$ and $\left.1 \mathrm{kHz}\right) .{ }^{24}$ Many works have reported that BFT, which was first synthesized by Galasso et al., ${ }^{25}$ presents a cubic perovskite-type structure with space group Pm $\overline{3} m(221)^{24-26}$ and the lattice parameter $a=4.056 \AA^{24,27}$ BFT can be used to modify other materials such as $\mathrm{BiFeO}_{3}{ }^{24}$ and $\mathrm{Ba}\left(\mathrm{Zr}_{0.05} \mathrm{Ti}_{0.95}\right) \mathrm{O}_{3}(\mathrm{BZT}),{ }^{27}$ and the properties of the modified ceramics have been improved. For example, the dielectric constants of the BZT-BFT solid solution were enhanced by $\mathrm{BFT}^{28}$

In the present research, new lead-free of $\mathrm{Bi}_{0.5}\left(\mathrm{Na}_{0.80^{-}}\right.$ $\left.\mathrm{K}_{0.20}\right)_{0.5} \mathrm{TiO}_{3}-0.03\left(\mathrm{Ba}_{0.70} \mathrm{Sr}_{0.03}\right) \mathrm{TiO}_{3}$ doped with $\mathrm{Ba}\left(\mathrm{Fe}_{0.5} \mathrm{Ta}_{0.5}\right) \mathrm{O}_{3}$ ceramics were synthesized with the aim of improving their electrical properties. The role of BFT content on the ceramic properties including phase formation, microstructure, electrical properties (i.e. dielectric, ferroelectric and piezoelectric, and the electric field-induced strain behavior) of the BNKT0.03BSrT ceramic were investigated. Furthermore, since many recent works have focused on energy storage materials due to global energy problems, thus the storage energy density behavior of the presented ceramics was also investigated.

\section{Experimental}

The conventional mixed oxide technique was used to synthesize the $(1-x)\left[\mathrm{Bi}_{0.5}\left(\mathrm{Na}_{0.80} \mathrm{~K}_{0.20}\right)_{0.5} \mathrm{TiO}_{3}-0.03\left(\mathrm{Ba}_{0.70} \mathrm{Sr}_{0.03}\right) \mathrm{TiO}_{3}\right]-$ $x \mathrm{Ba}\left(\mathrm{Fe}_{0.5} \mathrm{Ta}_{0.5}\right) \mathrm{O}_{3}$ or $(1-x)[\mathrm{BNKT}-0.03 \mathrm{BSrT}]-x \mathrm{BFT}$ powders. The analytical grade reagents of metal oxide powders, including $\mathrm{Na}_{2} \mathrm{CO}_{3}, \mathrm{Bi}_{2} \mathrm{O}_{3}, \mathrm{~K}_{2} \mathrm{CO}_{3}, \mathrm{TiO}_{2}, \mathrm{Fe}_{2} \mathrm{O}_{3}, \mathrm{SrCO}_{3}, \mathrm{BaCO}_{3}$, and $\mathrm{Ta}_{2} \mathrm{O}_{5}$ were used as starting materials. All carbonate powders were first dried at $120{ }^{\circ} \mathrm{C}$ for $24 \mathrm{~h}$ in order to eliminate any moisture. The raw materials of BNKT-0.03BSrT and BFT were stoichiometrically weighed, ball milled for $24 \mathrm{~h}$ in an ethanol solution, and then dried in an oven. Since there is a large difference in calcination temperatures between BNKT-0.03BSrT $\left(900^{\circ} \mathrm{C}\right)$ and BFT $\left(1200^{\circ} \mathrm{C}\right)$ powders, two calcination steps were employed i.e. the BNKT-0.03BSrT and BFT powders were synthesized separately. The resulting powders were weighed, mixed and then dried to obtained a powder of $(1-x)$ [BNKT-0.03BSrT] $-x$ BFT with $x=0,0.0,0.02$ and 0.03 mol fraction. A few drops of polyvinyl alcohol (PVA) binders (4 wt\%) were added to the obtained powders before being uniaxially pressed into discs 10 $\mathrm{mm}$ in diameter. The green pellets were sintered at $1125^{\circ} \mathrm{C}$ for 2 $\mathrm{h}$ by using a heating and cooling rate of $5{ }^{\circ} \mathrm{C} \mathrm{min}^{-1}$.

Bulk density was determined by the Archimedes' method. A scanning electron microscope (SEM, JEOL JSM-6335F) was used to study microstructural features of the ceramics. An X-ray diffractometer (XRD-Phillip, X-pert) was used to study the phase evolution of all ceramics. Grain size of the ceramics was carried out by using linear intercept method (ASTM no. E112-88). Before investigating the electrical measurements, all samples were polished into a parallel surface with $1 \mathrm{~mm}$ thickness. Silver paste was subjected onto both sides of the sample. Then the samples were heated at $700{ }^{\circ} \mathrm{C}$ for $30 \mathrm{~min}$ to form electrodes. Dielectric properties as a function of temperature $\left(25-400{ }^{\circ} \mathrm{C}\right)$ were carried out using a LCR-meter (HP model 4192A) at frequencies ranging from 1 to $1000 \mathrm{kHz}$. The ferroelectric properties were carried out by a Radiant Precision ferroelectric tester both at room temperature (RT) and high temperatures (HT) of $25-150{ }^{\circ} \mathrm{C}$. A maximum electric field of $50 \mathrm{kV} \mathrm{cm}{ }^{-1}$ at a frequency of $1 \mathrm{~Hz}$ was applied to each studied sample. Remanent polarization $\left(P_{\mathrm{r}}\right)$, maximum polarization $\left(P_{\max }\right)$, and coercive field $\left(E_{\mathrm{c}}\right)$ values were determined from the hysteresis loops or $P-E$ loops. By using data from ferroelectric properties, the energy storage density $(W)$ and energy storage coefficient $(\eta)$ values were also calculated. Strain-electric field $(S-E)$ data at RT were carried out using an optical displacement sensor (Fotonic Sensor model MTI-2100) injunction with a Radiant ferroelectric test system. A maximum electric field of $50 \mathrm{kV} \mathrm{cm}{ }^{-1}$ and a frequency of $0.1 \mathrm{~Hz}$ were used to measure the bipolar and unipolar strain curves. The maximum strain $\left(S_{\max }\right)$ and the negative strain $\left(S_{\text {neg }}\right)$ values were carried out from the bipolar curve. The normalized strain coefficient $d_{33}^{*}$ was also determined following: $d_{33}^{*}=S_{\max } / E_{\max }$. The electrostrictive coefficient $\left(Q_{33}\right)$ was determined from $S-P$ curves using equation: $S=$ $Q P^{2}$. For piezoelectric measurement, all samples were poled at 
RT with an applied DC electric field of $5 \mathrm{kV} \mathrm{mm}^{-1}$ (for $15 \mathrm{~min}$ ) and using silicone oil as the media. The low-field piezoelectric coefficient $\left(d_{33}\right)$ was determined by a $d_{33}$-meter.

\section{Results and discussion}

\section{Phase formation and microstructure}

Fig. 1(a) shows the X-ray diffraction patterns with different doping contents of the $(1-x)$ [BNKT-0.03BSrT] $-x$ BFT ceramics. Within the resolution limit of XRD, all ceramics exhibit a single phase of perovskite structure with no secondary phase, confirming that BFT has been incorporated into the BNKT0.03BSrT lattice to form solid solutions of the end compounds. For analyzing the phase transition process, the XRD patterns for selected narrow angular ranges of $2 \theta=39-41^{\circ}$ and $2 \theta=44-48^{\circ}$ are presented in Fig. 1 (b) and (c), respectively. The $x=0$ ceramic presents a mixed phase of rhombohedral and tetragonal structure, which is demonstrated by a slight splitting of the $(111)_{\mathrm{R}} /(1 \overline{1} 1)_{\mathrm{R}}$ at $2 \theta \sim 40^{\circ}$ and splitting of the $(200)_{\mathrm{T}} /(002)_{\mathrm{T}}$ peaks at $2 \theta \sim 46^{\circ}$. This result also agrees with the result observed by Ge et al. ${ }^{6}$ However, the coexistence of the mixed rhombohedral and tetragonal phases transforms into a tetragonal-rich phase at higher BFT contents. This can be evidenced by, the existence of the splitting $(200)_{\mathrm{T}} /(002)_{\mathrm{T}}$ peaks, and the merger of the $(111)_{\mathrm{R}} /(1 \overline{1} 1)_{\mathrm{R}}$ peak into a single $(111)_{\mathrm{PC}}$ peak, thus indicating that the amount of tetragonal phase is higher than that of the rhombohedral phase, with increasing BFT content. To check the appearance of the phase transformation in more detail, the tetragonality ratio $(c / a)$ was determined and its values are listed in Table 1. The $c / a$ value increases from 1.0105 for the $x=$

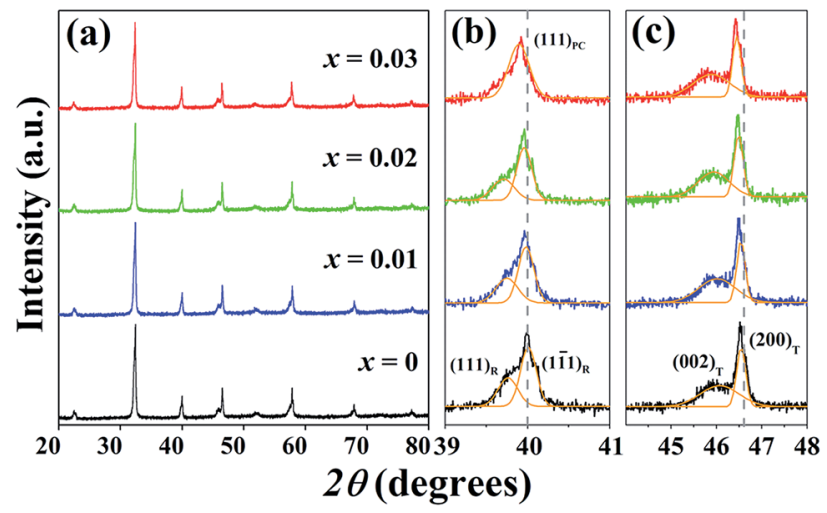

Fig. $1 X$-ray diffraction patterns of the $(1-x)$ [BNKT-0.03BSrT] $-x B F T$ ceramics where (a) $2 \theta=20-80^{\circ}$ (b) $2 \theta=39-41^{\circ}$ and (c) $2 \theta=44-48^{\circ}$.
0 ceramic to 1.0128 for the $x=0.03$ ceramic, as expected. Furthermore, the diffraction peaks gradually shift to a lower angle with increasing BFT content. This can be caused by the differences in the ionic radii between $\mathrm{Na}^{+}, \mathrm{Bi}^{3+}, \mathrm{K}^{+}, \mathrm{Sr}^{2+}$, and $\mathrm{Ba}^{2+}$ at the A-site and $\mathrm{Ti}^{4+}, \mathrm{Fe}^{3+}$, and $\mathrm{Ta}^{5+}$ at the B-site ${ }^{29}$ which, as a result, can induce a structural distortion such as an enlargement of unit cell size, as shown in Fig. 2. A similar peak slightly shifted by partial substitution of $\mathrm{Ba}^{2+}$ for $\left[\mathrm{Bi}_{0.5}\left(\mathrm{Na}_{0.80} \mathrm{~K}_{0.20}\right)\right]^{2+}$ and $\mathrm{Zr}^{4+}$ for $\mathrm{Ti}^{4+}$ was reported by Chen et al. ${ }^{30}$ in the BNKT-BZT system. They also found that the (110) peak shifted to lower $2 \theta$ angles could produce an increase in the lattice constant and the unit cell dimension with increasing BZT fraction.

SEM micrographs and their corresponding histogram of grain size distribution of the $(1-x)$ [BNKT-0.03BSrT] $-x$ BFT ceramics are shown in Fig. 3. The average grain size values are also summarized in Table 1. The SEM result confirms that all samples are dense with relatively high densities (5.80-5.86 $\left.\mathrm{g} \mathrm{cm}^{-3}\right)$. Furthermore, the porosity levels evident in the micrographs are noted to be consistent with the trend of measured density value, where the density increases with increasing BFT content. Most grains of all samples show a clear grain boundary with round and cubic shapes. The addition of BFT seems to have a slight influence on the microstructure as well as the average grain size of the BNKT-BSrT ceramics. The average grain size values of all samples are rather similar $(0.56-0.61 \mu \mathrm{m})$ and the grain size distribution shows a monomodal normal distribution. However, a slight narrow grain size distribution is noted for a ceramic containing a higher amount of BFT. This suggests that the microstructure can be improved by a BFT additive.

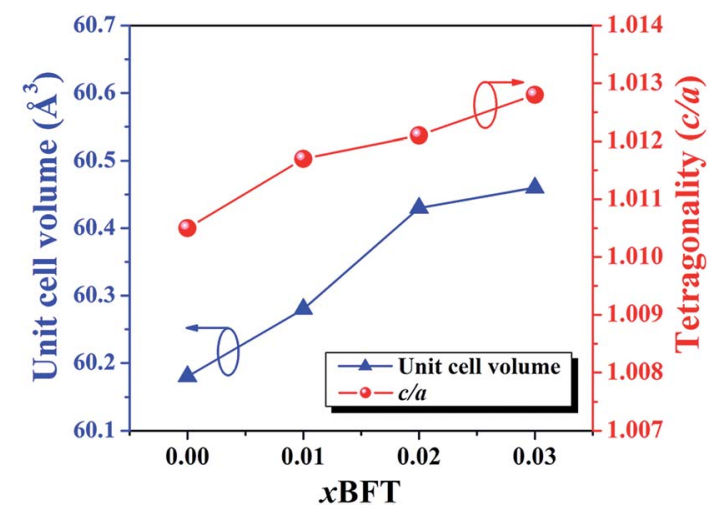

Fig. 2 Plots of unit cell volume and the tetragonality $(c / a)$ as functions of BFT content of the $(1-x)$ [BNKT-0.03BSrT] $-x$ BFT ceramics.

Table 1 Phase, physical, microstructure and dielectric properties of the $(1-x)[\mathrm{BNKT}-0.03 \mathrm{BS}$ TT] $-x \mathrm{BFT}$ ceramics

\begin{tabular}{lllllllll}
\hline$x$ & $\begin{array}{l}\text { Density } \\
\left(\mathrm{g} \mathrm{cm}^{-3}\right)\end{array}$ & $\begin{array}{l}\text { Relative } \\
\text { density }(\%)\end{array}$ & $c / a$ & $\begin{array}{l}\text { Unit cell } \\
\text { volume }\left(\AA^{3}\right)\end{array}$ & $\begin{array}{l}\text { Grain size } \\
(\mu \mathrm{m})\end{array}$ & $T_{\mathrm{m}}\left({ }^{\circ} \mathrm{C}\right)$ & $\begin{array}{l}\varepsilon_{\max } \\
(@ 1 \mathrm{kHz})\end{array}$ & $\delta_{\gamma}{ }^{a}(\mathrm{~K})$ \\
\hline 0 & 5.80 & 98 & 1.0105 & 60.18 & 0.61 & 316 & 5156 & 83 \\
0.01 & 5.83 & 98 & 1.0117 & 60.28 & 0.59 & 303 & 5151 & 91 \\
0.02 & 5.85 & 99 & 1.0121 & 60.43 & 0.58 & 292 & 4814 & 94 \\
0.03 & 5.86 & 99 & 1.0128 & 60.46 & 0.56 & 284 & 4716 & 117 \\
\end{tabular}

${ }^{a}$ Poled sample. ${ }^{b}$ Unpoled sample. 

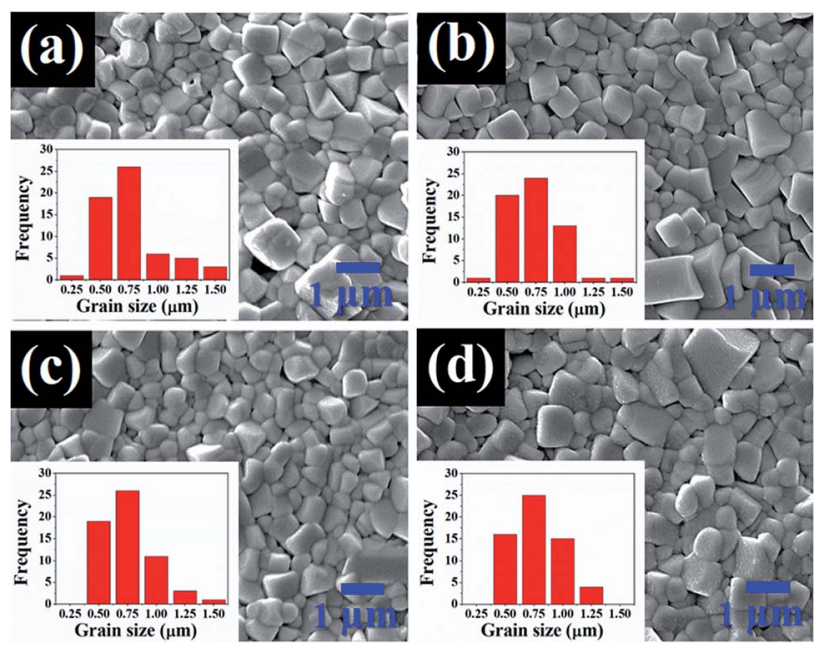

Fig. 3 SEM micrographs and their corresponding histograms of grain size distribution of the $(1-x)$ [BNKT-0.03BSrT] $-x B F T$ ceramics where (a) $x=0$, (b) $x=0.01$, (c) $x=0.02$, and (d) $x=0.03$.

\section{Dielectric properties}

Temperature dependence of the dielectric properties, including constant $\left(\varepsilon_{\mathrm{r}}\right)$ and dielectric loss $(\tan \delta)$ of the poled $(1-x)$ [BNKT-0.03BSrT]- $x$ BFT ceramics measured at different frequencies from 1-1000 $\mathrm{kHz}$ are shown in Fig. 4, and the related values are also listed in Table 1 . It can be seen that the $\varepsilon_{\mathrm{r}}$ versus temperature $\left(\varepsilon_{\mathrm{r}}-T\right)$ curves of all samples are rather similar. The $\varepsilon_{\mathrm{r}}-T$ curves for all ceramics exhibit two dielectric anomaly peaks at $\sim 100{ }^{\circ} \mathrm{C}$ and $300{ }^{\circ} \mathrm{C} . .^{31-33}$ Normally, the high temperature anomaly peak is called $T_{\mathrm{m}}$, where the dielectric constant reaches its maximum value. ${ }^{34-36}$ The lower anomaly peak is located near $T_{\mathrm{F}-\mathrm{R}}$, which is known as the ferroelectric (FE) to ergodic relaxor (ER) phase transition temperature. ${ }^{6}$ Normally, the $T_{\mathrm{F}-\mathrm{R}}$ can be usually carried out from the peak of $\tan \delta$ - $T$ curve of a poled sample. However, the $T_{\mathrm{F}-\mathrm{R}}$ could not be detected from the $\tan \delta$-T curves for this work. The $T_{\mathrm{m}}$ and $\varepsilon_{\max }$
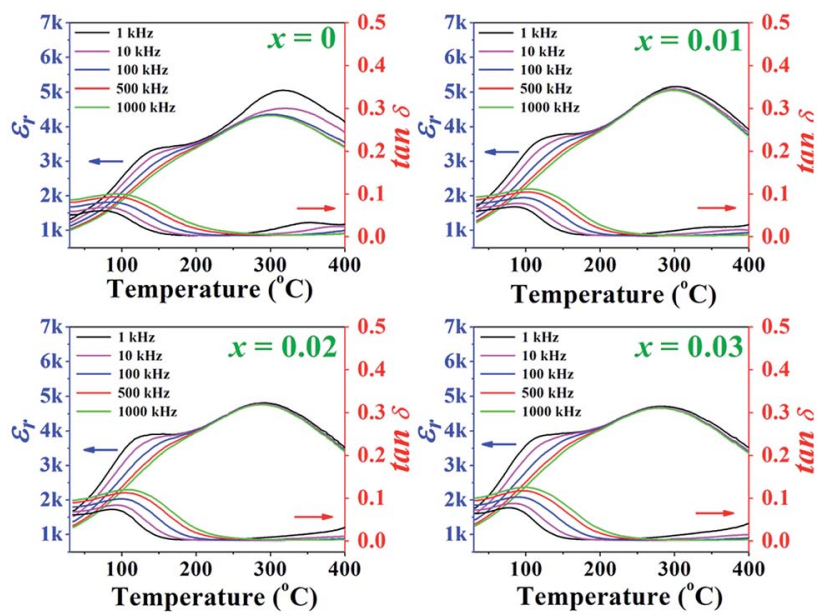

Fig. 4 Temperature dependence of the dielectric constant $\left(\varepsilon_{\mathrm{r}}\right)$ and dielectric loss $(\tan \delta)$ of the poled $(1-x)$ [BNKT-0.03BSrT]-xBFT ceramics measured at various frequencies from $1-1000 \mathrm{kHz}$ where $x$ $=0-0.03$. values of the $x=0$ ceramic in this study are observed from Fig. 4 to be 316 and 5156, respectively. The $\varepsilon_{\max }$ decreases with increasing BFT content. Furthermore, the $T_{\mathrm{m}}$ also shifts from $316^{\circ} \mathrm{C}$ for the $x=0$ ceramic to $284{ }^{\circ} \mathrm{C}$ the $x=0.03$ ceramic. This result also agrees with the results of previous report for other BNKT-based ceramics. ${ }^{34}$

To study the diffuse phase transition in this system, the diffuseness of the phase transition was calculated by a modified Curie-Weiss law eqn (1) which is given by ref. 37 and 38.

$$
\frac{\varepsilon_{\max }}{\varepsilon_{\mathrm{r}}}=1+\frac{\left(T-T_{\mathrm{m}}\right)^{2}}{2 \delta_{\gamma}{ }^{2}},
$$

where $\delta_{\gamma}$ is the diffuseness parameter. The $\delta_{\gamma}$ value can be carried out from the curve of $\ln \left(\varepsilon_{\max } / \varepsilon_{\mathrm{r}}-1\right) v s \cdot \ln \left(T-T_{\mathrm{m}}\right)^{2}$, where the curve should be linear. ${ }^{37}$ The $\delta_{\gamma}$ is used to compare the degree of diffuseness of the phase transition for many materials. The $\delta_{\gamma}$ values for poled and unpoled ceramics are summarized in Table 1. Based on Table 1, it can be seen that the addition of BFT has an effect on the degree of diffuseness, where the $\delta_{\gamma}$ value increases with increasing BFT content. This result corresponds to the previous work, ${ }^{39}$ which indicates that the addition of BFT produces a higher degree of diffuseness for the phase transition in the modified BNKT ceramics.

\section{Polarization and strain behaviors}

The $P-E$ hysteresis and bipolar strain-electric field $(S-E)$ loops measured at room temperature (RT) and electric field of $50 \mathrm{kV}$ $\mathrm{cm}^{-1}$ are shown in Fig. 5 and 6, respectively. The related values are also listed in Tables 2 and 3. The $x=0$ ceramic displays a small pinched loop with the maximum values of $P_{\max }=37.70$ $\mu \mathrm{C} \mathrm{cm}^{-2}, P_{\mathrm{r}}=21.74 \mu \mathrm{C} \mathrm{cm}^{-2}$ and $E_{\mathrm{c}}=12.87 \mathrm{kV} \mathrm{cm}^{-1}$. The $S-E$ curve for this sample also exhibits a butterfly-shaped loop. The $S_{\max }$ and $d_{33}^{*}$ of this ceramic are $0.33 \%$ and $650 \mathrm{pm} \mathrm{V}^{-1}$, respectively. The ferroelectric loop indicates a ferroelectric domain switching at $E_{\mathrm{c}}$, where the largest $S_{\text {neg }}$ is $-0.11 \%$. However, this ceramic sample should contain a mixed phase
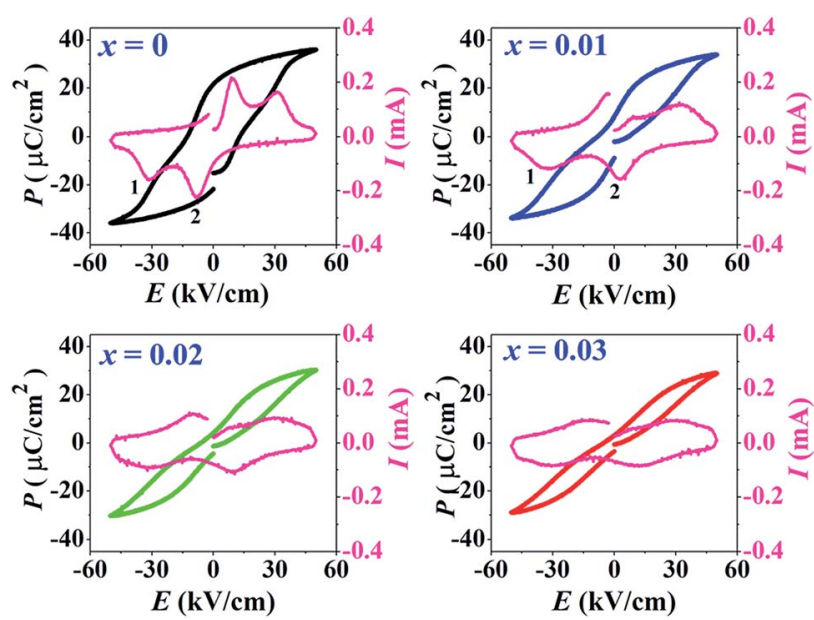

Fig. 5 Polarization-electric field $(P-E)$ hysteresis loops and currentelectric field $(I-E)$ loops of the $(1-x)$ [BNKT $-0.03 B S r T]-x B F T$ ceramics where $x=0-0.03$, measured at RT under an electric field of $50 \mathrm{kV}$ $\mathrm{cm}^{-1}$ and a frequency of $1 \mathrm{~Hz}$. 

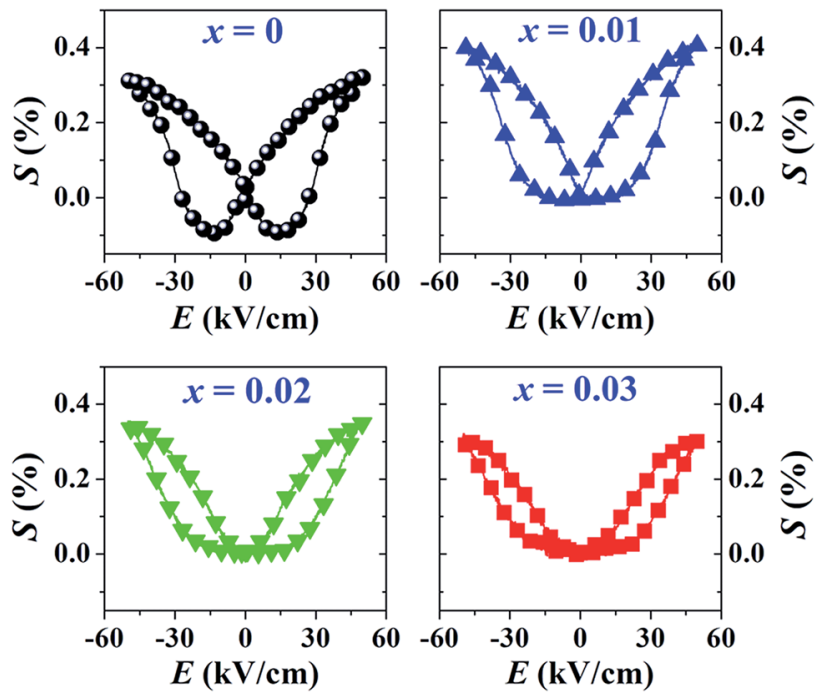

Fig. 6 Bipolar strain-electric field $(S-E)$ loops of the $(1-x)$ [BNKT$0.03 \mathrm{BSrT}]-x \mathrm{BFT}$ ceramics where $x=0-0.03$, measured at RT under an electric field of $50 \mathrm{kV} \mathrm{cm}^{-1}$ and a frequency of $0.1 \mathrm{~Hz}$.

between $\mathrm{FE}$ and $\mathrm{ER}$, since the $P-E$ loop presents a small pinched shape. For the $x=0.01$ ceramic, however, the $P-E$ hysteresis loop exhibits a more pinched loop with a decrease of $P_{\mathrm{r}}$ from $21.74 \mu \mathrm{C} \mathrm{cm}^{-2}$ to $8.15 \mu \mathrm{C} \mathrm{cm}^{-2}$ and $E_{\mathrm{c}}$ from $12.87 \mathrm{kV} \mathrm{cm}^{-1}$ to $7.34 \mathrm{kV} \mathrm{cm}^{-1}$. The hysteresis loop shows a clear pinching-type character with further increasing BFT content, similarly observed in previous works. ${ }^{6,35}$ The pinched $P-E$ loops corresponded with the two current peaks (denoted as "1" and " 2 ") in the $I-E$ curves (Fig. 5), where it has been suggested that this evidence indicates a formation of ER phase. ${ }^{14,36}$

The more pinched $P-E$ loops result also corresponds to a large electric field-induced strain response with $S_{\max }$ of $0.42 \%$ and $d_{33}^{*}$ of $840 \mathrm{pm} \mathrm{V}^{-1}$ along with a drastic reduction in $S_{\text {neg }}$ from $-0.11 \%$ to $0 \%$ for the $x=0.01$ ceramic in bipolar $S-E$ loops. This enhancement is also confirmed by the unipolar $S-E$
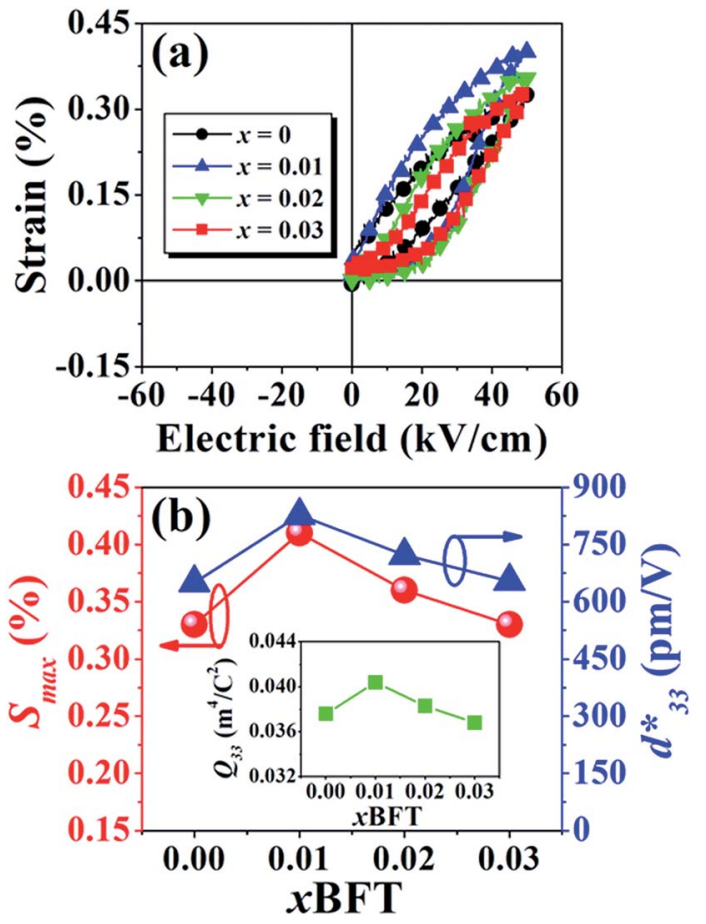

Fig. 7 Plots of (a) unipolar strain-electric field $(S-E)$ loops of the $(1-x)$ [BNKT-0.03BSrT] $-x$ BFT ceramics where $x=0-0.03$, measured at RT under an electric field of $50 \mathrm{kV} \mathrm{cm}^{-1}$ and a frequency of $0.1 \mathrm{~Hz}$ and (b) plots of the maximum strain $\left(S_{\max }\right)$ and normalized strain coefficient $\left(d_{33}^{*}=S_{\max } / E_{\max }\right)$ as a function of BFT content (inset: $Q_{33}$ value as a function of BFT content).

loops, as shown in Fig. 7(a). It is seen that the unipolar $S-E$ loops for all compositions show a similar trend as compared to that of the bipolar $S-E$ loops, where the maximum strain value of the unipolar strain is $0.42 \%$ for the $x=0.01$ ceramic (Fig. 7(b)). The pinching of the $P-E$ hysteresis loops with rapid reductions of $P_{\mathrm{r}}$ and $E_{\mathrm{c}}$ can be correlated with the increase of $S_{\max }$ along with a drastic reduction in $S_{\text {neg }}$. This may be related

Table 2 Ferroelectric and energy storage density properties of the $(1-x)$ [BNKT $-0.03 \mathrm{BS} \mathrm{TT}]-x \mathrm{BFT}$ ceramics

\begin{tabular}{|c|c|c|c|c|c|c|c|c|c|}
\hline$x$ & $P_{\max }\left(\mu \mathrm{C} \mathrm{cm}^{-2}\right)$ & $P_{\mathrm{r}}\left(\mu \mathrm{C} \mathrm{cm}{ }^{-2}\right)$ & $E_{\mathrm{c}}\left(\mathrm{kV} \mathrm{cm}^{-1}\right)$ & $W^{a}\left(\mathrm{~J} \mathrm{~cm}^{-3}\right)$ & $W^{b}\left(\mathrm{~J} \mathrm{~cm}^{-3}\right)$ & $W^{C}\left(\mathrm{~J} \mathrm{~cm}^{-3}\right)$ & $\eta^{a}(\%)$ & $\eta^{b}(\%)$ & $\eta^{c}(\%)$ \\
\hline 0 & 37.70 & 21.74 & 12.87 & 0.20 & 0.54 & 0.60 & 20.0 & 69.5 & 81.2 \\
\hline 0.01 & 35.65 & 8.15 & 7.34 & 0.37 & 0.61 & 0.61 & 38.6 & 80.0 & 87.4 \\
\hline 0.03 & 29.18 & 3.15 & 4.77 & 0.49 & 0.65 & 0.63 & 60.7 & 90.4 & 92.1 \\
\hline
\end{tabular}

${ }^{a}$ Ferroelectric data obtained at high temperature of $25{ }^{\circ} \mathrm{C}$ and a frequency of $1 \mathrm{~Hz} \cdot{ }^{b}$ Ferroelectric data obtained at high temperature of $120{ }^{\circ} \mathrm{C}$ and a frequency of $1 \mathrm{~Hz} .{ }^{c}$ Ferroelectric data obtained at high temperature of $150{ }^{\circ} \mathrm{C}$ and a frequency of $1 \mathrm{~Hz}$.

Table 3 Piezoelectric properties of the $(1-x)$ [BNKT-0.03BSrT] $-x$ BFT ceramics

\begin{tabular}{|c|c|c|c|c|c|c|}
\hline$x$ & $S_{\max }(\%)$ & $S_{\text {neg }}(\%)$ & $d_{33}^{*}\left(\mathrm{pm} \mathrm{V}^{-1}\right)$ & $H(\%)$ & $Q_{33}\left(\mathrm{~m}^{4} \mathrm{C}^{-2}\right)$ & $d_{33}\left(\mathrm{pC} \mathrm{N}^{-1}\right)$ \\
\hline 0 & 0.33 & -0.11 & 650 & 78.9 & 0.0376 & 172 \\
\hline 0.01 & 0.42 & 0 & 840 & 55.0 & 0.0404 & 38 \\
\hline 0.03 & 0.32 & 0 & 654 & 39.3 & 0.0368 & 28 \\
\hline
\end{tabular}


with a phase transition from a ferroelectric (FE) to an ergodic relaxor (ER) phase, accompanied by the disruption of longrange ferroelectric order with increasing BFT content. ${ }^{6}$ Normally, the free energy of FE and ER phases is comparable under zero field, thus it can be easily induced by an external electric field to become saturated. ${ }^{36}$ Therefore, ER phase can be transformed reversibly into $\mathrm{FE}$ phase by an external electric field. This behaviour consists with the work done by Dong et al. ${ }^{40}$ who also reported that the $(1-x)\left(0.8 \mathrm{Bi}_{1 / 2} \mathrm{Na}_{1 / 2} \mathrm{TiO}_{3}-0.2 \mathrm{Bi}_{1 / 2} \mathrm{~K}_{1 /}\right.$ $\left.{ }_{2} \mathrm{TiO}_{3}\right)-x \mathrm{BiMg}_{2 / 3} \mathrm{Nb}_{1 / 3} \mathrm{O}_{3}$ or (BNT-BKT)-BMN system produced a large strain response when a small amount of $\mathrm{BMN}$ was added into the BNT-BKT ceramic. The addition of $2 \mathrm{~mol} \% \mathrm{BMN}$ into the BNT-BKT ceramic shows a pronounced ergodic relaxor (ER) characteristic, which is confirmed by the absence of $S_{\text {neg, }}$, the pinched $P-E$ loop and the double current peaks of $I-E$ loop. However, in the present work when $x>0.01$, the strain is reduced gradually. Therefore, the small amount of BFT additive has effects on the piezoelectric properties of the BNKT$0.03 \mathrm{BSrT}$ ceramics. It should be noted that the $S_{\max }$ in this work $(x=0.01)$ is considered high when compared with other leadfree piezoelectric ceramics (see Table 4$) \cdot{ }^{\mathbf{1 8 4 1 - 4 8}}$ Furthermore, the bipolar strain loops for the present work exhibit a low antisymmetry in their shape compared to many previous works for the giant strain response which showed high anti-symmetry. ${ }^{\mathbf{4 2 , 4 5}}$ In the present work, an average maximum strain $\left(\bar{S}_{\max }\right)$ was calculated to be used as a parameter to check for overall averaged maximum strain of the bipolar strain loop, where $\bar{S}_{\max }$ averaged from maximum strain between the right and left hand sides of the bipolar strain loop. The result is also shown in Table 4. The obtained $\bar{S}_{\text {max }}$ for the present work is considered high for the lead-free piezoelectric ceramics.

The $Q_{33}$ was determined from the slope of $S v s . P^{2}$ curve. ${ }^{49,50}$ The plotting of $Q_{33}$ value as a function of BFT content is shown in inset of Fig. 7(b). The highest $Q_{33}$ of $0.040 \mathrm{~m}^{4} \mathrm{C}^{-2}$ is noted for the $x=0.01$ ceramic. It is evident that the currently presented $Q_{33}$ value is highly competitive to many materials. ${ }^{51-58}$ In addition, a comparison of the room temperature $Q_{33}$ and normalized $Q_{33}\left(Q_{33} / E\right)$ values with other lead-based and lead-free BNTbased electrostrictive materials are summarized in Table $5 .^{51-58}$ It should be noted that the $Q_{33} / E$ value for the present work is very high for both lead-based and lead-free BNT-based piezoelectric materials. Therefore, the $(1-x)$ [BNKT-0.03BSrT]- $x$ BFT compound may be a promising candidate for new electromechanical devices due to its giant $Q_{33}$ value.

Normally for the actuator applications, a large strain with low hysteresis is necessary. The degree of strain hysteresis $(H)$ can be determined from the following equation: ${ }^{38,59}$

$$
H=\frac{\Delta S_{\frac{E_{\max }}{2}}}{S_{\max }} \times 100 \%
$$

where the $\Delta S_{E_{\max } / 2}$ is the strain deviation during the application and removal of the field which is carried out at half of the maximum electric field. The $H$ values of all ceramics are summarized in Table 3. It was found that the $H$ decreases with

Table 4 Comparison of $S_{\max }$ and $d_{33}^{*}$ values of the $(1-x)$ [BNKT-0.03BSrT]-xBFT $(x=0.01)$ with other lead-free ceramics

\begin{tabular}{|c|c|c|c|c|c|}
\hline Systems & $S_{\max }(\%)$ & $\bar{S}_{\max }(\%)$ & $d_{33}^{*}\left(\mathrm{pm} \mathrm{V}^{-1}\right)$ & $E_{\max }\left(\mathrm{kV} \mathrm{cm}^{-1}\right)$ & Ref. \\
\hline $0.99[\mathrm{BNKT}-0.03 \mathrm{BSrT}]-0.01 \mathrm{BFT}$ & 0.42 & 0.42 & 827 & 50 & This work \\
\hline BNKT-BST-La $x$ & 0.39 & 0.39 & 650 & 60 & 18 \\
\hline $\left.\mathrm{Bi}_{1 / 2}\left(\mathrm{Na}_{0.8} \mathrm{~K}_{0.2}\right)_{1 / 2}\right]\left(\mathrm{Ti}_{1-x} \mathrm{Ta}_{x}\right) \mathrm{O}_{3}, x=0.015$ & 0.62 & 0.42 & 1240 & 50 & 42 \\
\hline BNKT-BST-Nb $_{x}, x=0.02$ & 0.38 & 0.38 & 634 & 60 & 43 \\
\hline $\mathrm{Bi}_{0.5}\left(\mathrm{Na}_{0.78} \mathrm{~K}_{0.22}\right)_{0.5} \mathrm{TiO}_{3}-0.01\left(\mathrm{Bi}_{0.5} \mathrm{La}_{0.5}\right) \mathrm{AlO}_{3}$ & 0.40 & 0.40 & 579 & 70 & 44 \\
\hline $\mathrm{Bi}_{0.5}\left(\mathrm{Na}_{0.80} \mathrm{~K}_{0.20}\right)_{0.5} \mathrm{TiO}_{3}-0.05 \mathrm{Ba}\left(\mathrm{Ti}_{0.90} \mathrm{Sn}_{0.10}\right) \mathrm{O}_{3}$ & 0.36 & 0.36 & 649 & 55 & 47 \\
\hline$\left[0.93\left(\mathrm{Bi}_{0.5} \mathrm{Na}_{0.5}\right) \mathrm{TiO}_{3}-0.07 \mathrm{BaTiO}_{3}\right]-\mathrm{Pr}$ & 0.43 & 0.42 & 770 & 50 & 48 \\
\hline
\end{tabular}

Table 5 Comparison of $Q_{33}$ and $Q_{33} / E$ values of the $(1-x)$ [BNKT-0.03BSrT]-xBFT $(x=0.01)$ with other lead and lead-free ceramics

\begin{tabular}{|c|c|c|c|c|c|}
\hline Systems & $S_{\max }(\%)$ & $Q_{33}\left(\mathrm{~m}^{4} \mathrm{C}^{-2}\right)$ & $Q_{33} / E_{\max }\left(\mathrm{m}^{5} \mathrm{C}^{-2} \mathrm{~V}\right) \times 10^{-9}$ & $\begin{array}{l}E \\
\left(\mathrm{kV} \mathrm{cm}^{-1}\right)\end{array}$ & Ref. \\
\hline $0.99[\mathrm{BNKT}-0.03 \mathrm{BSrT}]-0.01 \mathrm{BFT}$ & 0.42 & 0.0404 & 8.08 & 50 & This work \\
\hline $\mathrm{Pb}\left(\mathrm{Mg}_{1 / 2} \mathrm{Nb}_{1 / 2}\right) \mathrm{O}_{3}$ & - & 0.023 & - & - & 51 \\
\hline PLZT 8/65/35 & 0.16 & 0.015 & 5.00 & 30 & 52 \\
\hline 0.96BNKT-0.04BNiT & 0.38 & 0.0250 & 4.17 & 60 & 53 \\
\hline $0.95 \mathrm{BNKT}-0.05 \mathrm{BNiT}$ & 0.32 & 0.0300 & 5.00 & 60 & 53 \\
\hline N44B48T94-6BT [or $\left.\left(\mathrm{Na}_{y}, \mathrm{Bi}_{z}\right) \mathrm{Ti}_{1-x} \mathrm{O}_{3}(1-x)-x \mathrm{BaTiO}_{3}\right]$ & 0.48 & 0.0260 & 3.71 & 70 & 54 \\
\hline $8 \%$ Sn-doped $\mathrm{Bi}_{1 / 2}\left(\mathrm{Na}_{0.82} \mathrm{~K}_{0.18}\right)_{1 / 2} \mathrm{TiO}_{3}$ & 0.14 & 0.0230 & 3.83 & 60 & 55 \\
\hline BNKT100y- $x$ KNN $(y=0.20, x=0.16)$ & 0.10 & 0.0250 & 3.12 & 80 & 56 \\
\hline$(0.94-x) \mathrm{BNT}-0.06 \mathrm{BT}-x \mathrm{KNN}, x=0.20$ & 0.09 & 0.0260 & 3.25 & 80 & 57 \\
\hline $\mathrm{Bi}_{0.5-x} \mathrm{La}_{x} \mathrm{Na}_{0.40} \mathrm{~K}_{0.10} \mathrm{Ti}_{0.98} \mathrm{Zr}_{0.02} \mathrm{O}_{3}, x=0.02$ & 0.42 & 0.0360 & 6.00 & 60 & 58 \\
\hline
\end{tabular}


Table 6 Comparisons of the degree of strain hysteresis $(H)$ value of the $(1-x)$ [BNKT-0.03BSrT] $-x B F T(x=0.01$ and $x=0.03)$ with other leadfree ceramics

\begin{tabular}{|c|c|c|c|c|}
\hline Systems & $H(\%)$ & $S_{\max }(\%)$ & $d_{33}^{*}\left(\mathrm{pm} \mathrm{V}^{-1}\right)$ & Ref. \\
\hline $0.99[\mathrm{BNKT}-0.03 \mathrm{BSrT}]-0.01 \mathrm{BFT}$ & 55.0 & 0.42 & 840 & This work \\
\hline $0.97[\mathrm{BNKT}-0.03 \mathrm{BSrT}]-0.03 \mathrm{BFT}$ & 39.3 & 0.32 & 654 & This work \\
\hline $\mathrm{Bi}_{1 / 2}\left(\mathrm{Na}_{0.82} \mathrm{~K}_{0.12}\right)_{1 / 2} \mathrm{Ti}_{1-x \%}\left(\mathrm{Fe}_{0.5} \mathrm{Nb}_{0.5}\right)_{x \%} \mathrm{O}_{3}, x=5 \%$ & 57.0 & 0.46 & 660 & 32 \\
\hline BNKT20-1.5SZ & 51.6 & 0.39 & 488 & 60 \\
\hline BNT-BKT-5La & 60.3 & 0.38 & 857 & 61 \\
\hline BNT-25ST & 45.8 & 0.29 & 650 & 62 \\
\hline BNKT-3 mol\% CZ & 49.0 & 0.37 & 603 & 63 \\
\hline BNKT-2 mol\% BCZ & 25.0 & 0.30 & 549 & 63 \\
\hline (Ho,Sb)-modified $\left(\mathrm{Bi}_{0.5} \mathrm{Na}_{0.5}\right)_{0.945} \mathrm{Ba}_{0.065} \mathrm{TiO}_{3}$ & 39.0 & 0.37 & 463 & 64 \\
\hline BNBT6.5-100x $\mathrm{ES}, x=0.50 \%$ & 39.0 & 0.40 & 500 & 65 \\
\hline BNT-BKT- $x$ BZT, $x=0.02$ & 40.0 & 0.32 & 503 & 66 \\
\hline
\end{tabular}

increasing BFT concentration. The lowest hysteresis of $39.3 \%$ is obtained at $x=0.03$ @ $50 \mathrm{kV} \mathrm{cm}{ }^{-1}$, which reveals that BFT doping obviously reduces the strain hysteresis. A comparison of the $H$ value for selected ceramic samples with other lead-free ceramics is shown in Table 6. ${ }^{32,60-66}$ The result clearly demonstrates that the $H$ value of the present work is low when compared to that of many previous works (for the lead-free piezoceramics with $d_{33}^{*}$ value $>450 \mathrm{pm} \mathrm{V}^{-1}$ ). This suggests that a BFT modifier can improve the actuating performance. ${ }^{38}$

\section{Polarization-temperature analysis}

Temperature dependence of polarization-electric field $(P-E)$ hysteresis loops of the $(1-x)$ [BNKT-0.03BSrT]- $x$ BFT ceramics where $x=0-0.03$, measured under an electric field of $50 \mathrm{kV}$ $\mathrm{cm}^{-1}$ and a frequency of $1 \mathrm{~Hz}$ is shown in Fig. 8. It can be seen that the $P-E$ hysteresis loop for the $x=0$ ceramic shows slightly pinched loops at $\mathrm{RT}\left(25^{\circ} \mathrm{C}\right)$. When the temperature increases to $120-150{ }^{\circ} \mathrm{C}$, the $P-E$ hysteresis loops become more pinched, confirming that the ferroelectric to relaxor phase transition is induced by thermal activation, thus leaving an ergodic relaxor

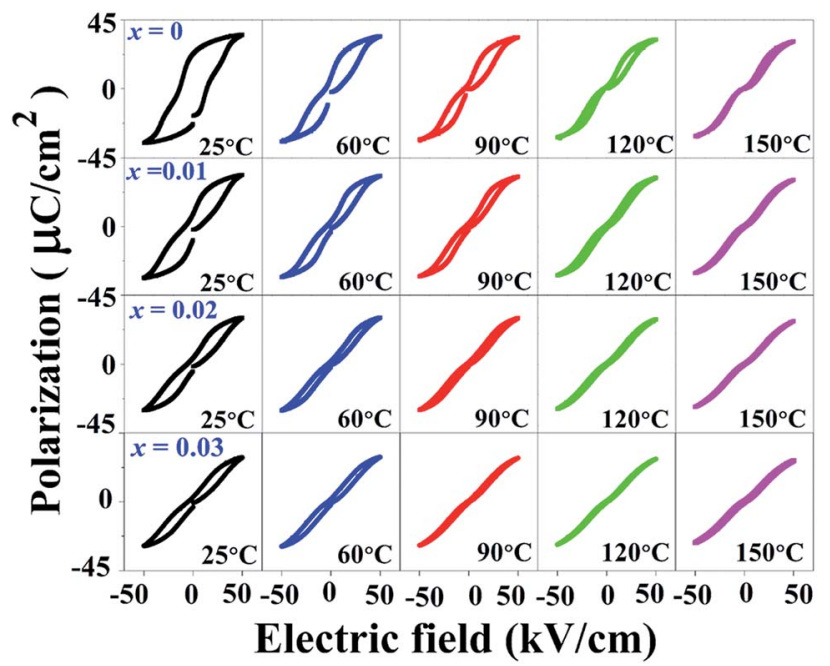

Fig. 8 Temperature dependence on polarization-electric field $(P-E)$ hysteresis loops of the $(1-x)[B N K T-0.03 B S r T]-x B F T$ ceramics where $x=0-0.03$, measured under an electric field of $50 \mathrm{kV} \mathrm{cm}^{-1}$ and a frequency of $1 \mathrm{~Hz}$.
(ER) state at zero electric field. ${ }^{67-69}$ On the other hand, the modified ceramics $(x \geq 0.01)$, exhibit an ER characteristic at RT. With further increasing temperature, the drastic decrease in both $P_{\mathrm{r}}$ and $E_{\mathrm{c}}$ values may also be related to the onset of strong ergodicity. ${ }^{68}$ Thus, both chemical modification and temperature can disrupt the FE long-range order leading to a decrease in the polarization states. ${ }^{68}$ This phenomenon agrees with that observed in many lead-free piezoelectric materials. ${ }^{40,69}$ Dong
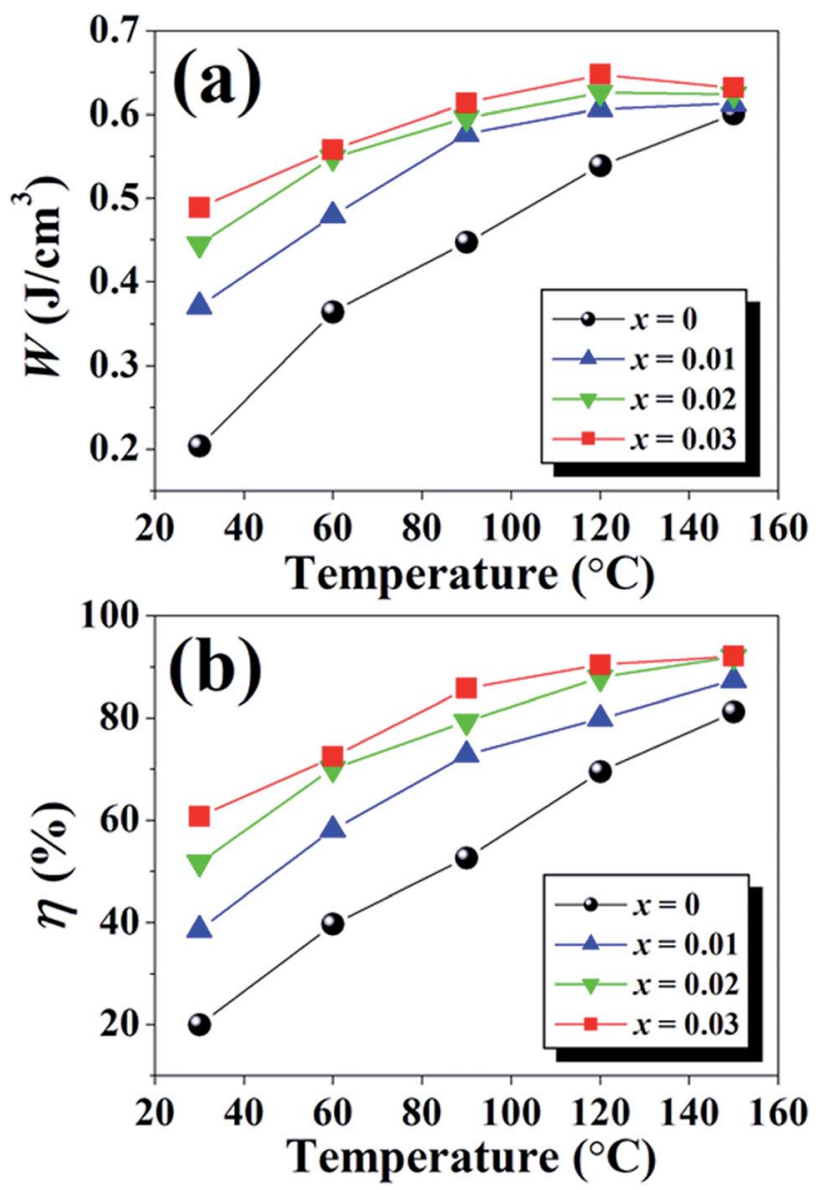

Fig. 9 Plots of (a) energy storage density $(W)$ and (b) energy storage coefficient $(\eta)$ as a function of temperature of the $(1-x)$ [BNKT$0.03 \mathrm{BS} r \mathrm{~T}]-x \mathrm{BFT}$ ceramics. 
Table 7 Comparison of $W$ and W/E of the $(1-x)$ [BNKT-0.03BSrT]-xBFT ceramics $(x=0.03)$ with other lead-free ceramics

\begin{tabular}{|c|c|c|c|c|c|}
\hline Systems & $\begin{array}{l}W \\
\left(\mathrm{~J} \mathrm{~cm}^{-3}\right)\end{array}$ & $\begin{array}{l}E \\
\left(\mathrm{kV} \mathrm{mm}^{-1}\right)\end{array}$ & $\begin{array}{l}W / E \\
\left(\mu \mathrm{C} \mathrm{mm}{ }^{-2}\right)\end{array}$ & $\eta(\%)$ & Ref. \\
\hline 0.97[BNKT-0.03BSrT] $-0.03 \mathrm{BFT}$ @ $120{ }^{\circ} \mathrm{C}$ & 0.65 & 5 & 0.13 & 90.4 & This work \\
\hline $0.96 \mathrm{BNKT}-0.04 \mathrm{MN}$ & 0.65 & 7 & 0.09 & 34.2 & 38 \\
\hline $0.92 \mathrm{BNKT}-0.08 \mathrm{AN}$ & 1.41 & 10.5 & 0.13 & - & 70 \\
\hline Nb-modified 0.96( $\left(\mathrm{Bi}_{0.5} \mathrm{Na}_{0.84} \mathrm{~K}_{0.16} \mathrm{TiO}_{3}\right)-0.04 \mathrm{SrTiO}_{3}$ & 1.00 & 6 & 0.17 & $>70$ & 72 \\
\hline $0.94 \mathrm{Bi}_{0.47} \mathrm{Na}_{0.47} \mathrm{Ba}_{0.06} \mathrm{TiO}_{3}-0.06 \mathrm{KNbO}_{3}$ & 0.89 & 10 & 0.09 & - & 73 \\
\hline$(0.9-x)\left[0.92 \mathrm{Bi}_{0.5} \mathrm{Na}_{0.5} \mathrm{TiO}_{3}-0.08 \mathrm{BaTiO}_{3}\right]-x \mathrm{SrZrO}_{3}-0.10 \mathrm{NaNbO}_{3}, x=0.08$ & 0.95 & 11 & 0.09 & 66.0 & 74 \\
\hline $0.92\left(0.65 \mathrm{BaTiO}_{3}-0.35 \mathrm{Bi}_{0.5} \mathrm{Na}_{0.5} \mathrm{TiO}_{3}\right)-0.08 \mathrm{Na}_{0.73} \mathrm{Bi}_{0.09} \mathrm{NbO}_{3}$ & 1.70 & 17.2 & 0.10 & 82.0 & 75 \\
\hline BNTBT-0.20NBN & 1.36 & 13.6 & 0.10 & 73.9 & 76 \\
\hline$\left(\mathrm{Bi}_{0.5} \mathrm{Na}_{0.5}\right) \mathrm{TiO}_{3}-0.10 \mathrm{KNbO}_{3}$ & 1.17 & 10.4 & 0.11 & - & 77 \\
\hline $0.7 \mathrm{SrTiO}_{3}-0.3\left(0.65 \mathrm{BaTiO}_{3}-0.35 \mathrm{Bi}_{0.5} \mathrm{Na}_{0.5} \mathrm{TiO}_{3}\right)$ & 1.40 & 19.6 & 0.07 & 90.0 & 78 \\
\hline $0.95(\mathrm{BNTBT})-0.05 \mathrm{KN}$ & 0.64 & 6 & 0.11 & 84 & 79 \\
\hline $0.99[0.7 \mathrm{BNT}-0.3 \mathrm{BST}]-0.01 \mathrm{NN}$ & 1.03 & 8.5 & 0.12 & 85.8 & 80 \\
\hline$(\mathrm{BNT}-6 \mathrm{BT})-\mathrm{NBN}$ & 1.40 & 14.2 & 0.11 & 66.3 & 81 \\
\hline
\end{tabular}

et $a .^{40}$ also studied the temperature dependence of $P-E$ hysteresis loops of the lead-free $(1-x)\left(0.8 \mathrm{Bi}_{1 / 2} \mathrm{Na}_{1 / 2} \mathrm{TiO}_{3}-0.2 \mathrm{Bi}_{1 /}\right.$ $\left.{ }_{2} \mathrm{~K}_{1 / 2} \mathrm{TiO}_{3}\right)-x \mathrm{BiMg}_{2 / 3} \mathrm{Nb}_{1 / 3} \mathrm{O}_{3}$ ceramics. With increasing temperature, the $P_{\mathrm{r}}$ and $E_{\mathrm{c}}$ values decrease gradually while $P_{\max }$ slight changed and the $P-E$ hysteresis loop showed severe pinches. This indicated the presence of an ergodic relaxor (ER) state, i.e. there exists a temperature-caused ferroelectric-to-relaxor phase transformation in their work.

\section{Energy storage density}

The polarization and dielectric breakdown strength are two important parameters related to the energy storage performance. As is known to all, the BNT-BKT ceramics with high $P_{\mathrm{r}}$ of $34 \mu \mathrm{C} \mathrm{cm}^{-2}$ and low breakdown field $\left(E_{\mathrm{b}} \sim 50 \mathrm{kV} \mathrm{cm}{ }^{-1}\right)$ are difficult to a satisfactory characteristic for high energy storage applications. $^{\text {70 }}$ Therefore, the design of BNT-BKT energy storage materials with low $P_{\mathrm{r}}$, large $P_{\max }$ as well as the improvement of $E_{\mathrm{b}}$ become two critical issues.

To evaluate the capability of the studied ceramics for energy storage applications, the energy storage density $(W)$ was calculated from the $P-E$ hysteresis loop as shown in the following equation: ${ }^{70,71}$

$$
W=\int_{P_{\mathrm{r}}}^{P_{\max }} E \mathrm{~d} P,
$$

where $E$ is the electric field, $P$ the polarization, $P_{\max }$ the maximum polarization, and $P_{\mathrm{r}}$ is the remnant polarization. For practical applications, higher energy storage efficiencies $(\eta)$ are required. The $\eta$ value is calculated by using the following formula: ${ }^{68,72}$

$$
\eta(\%)=\frac{W}{W+W_{\text {loss }}} \times 100,
$$

where energy loss density is denoted as $W_{\text {loss }}$. In this work, the energy storage density properties are summarized in Table 2. At RT, the $W$ and $\eta$ of the $x=0$ ceramic are $0.20 \mathrm{~J} \mathrm{~cm}^{-3}$ and $20.0 \%$, respectively. In this composition, the high $E_{\mathrm{c}}$ and low $P_{\max }-P_{\mathrm{r}}$ values are observed, which led to a low energy storage density, high energy loss, and low efficiency. ${ }^{72}$ The $x=0.01$ ceramic with a pinched $P-E$ hysteresis loop shows relatively high $W=0.37 \mathrm{~J} \mathrm{~cm}^{-3}$ and $\eta=38.6 \%$ values when compared with those observed for the $x=0$ ceramic. This improvement can be related with the decreases in $P_{\mathrm{r}}$, and slight invariant $P_{\max }$ with the degradation of the long range $\mathrm{FE}$ order and a relatively easy reorientation of the micro-domains. ${ }^{72}$ The $W$ and $\eta$ values increase with increasing BFT content and exhibit the maximum values of $0.49 \mathrm{~J} \mathrm{~cm}^{-3}$ and $60.7 \%$ at the electric field of $5 \mathrm{kV} \mathrm{mm}{ }^{-1}$ for the $x=0.03$ ceramic. These values are also higher than the value obtained for the $x=0$ sample by $\sim 145 \%$ and $203 \%$, respectively. In addition, the $W$ and $\eta$ values as a function of temperature of the $(1-x)$ [BNKT-0.03BSrT]$x$ BFT ceramics are presented in Fig. 9. It can also be seen that the $W$ and $\eta$ increase with increasing temperature for all compositions and reach the maximum value of $\sim 0.65 \mathrm{~J} \mathrm{~cm}^{-3}$ and $90.4 \%$ at $120{ }^{\circ} \mathrm{C}$ for the $x=0.03$ ceramic. These obtained $W$ values are close to the value obtained in $\mathrm{Bi}_{0.48} \mathrm{La}_{0.02} \mathrm{NKTZ}$ ceramics $\left(W \sim 0.63 \mathrm{~J} \mathrm{~cm}^{-3}\right.$, at $\left.\mathrm{RT}\right)$ as reported by Butnoi et $a .^{58}$

A comparison of normalized energy storage density $(W / E)$ with the previous reports is presented in Table $7 .^{38,70,72-81}$ The comparison of $W / E$ value with previous results clearly shows the superiority of this composition $(x=0.03)$ in terms of high $W / E=$ $0.13 \mu \mathrm{C} \mathrm{mm} m^{-2}$ and $\eta=90.4 \%$. The obtained $W / E$ value is high for Bi-based piezoelectric ceramics. Based on the obtained results, it is suggested that these synthesized ceramics are promising materials for actuator, high electric power and energy storage applications. ${ }^{72,77}$

\section{Conclusions}

In this work, the BNKT-0.03BSrT doped with BFT ceramics have been successfully synthesized by a solid-state mixed oxide method. The coexistence of rhombohedral and tetragonal phases is present throughout the entire compositional range, while a dominant tetragonal-rich phase is observed at a higher BFT content. The $x=0.01$ ceramic shows the high $S_{\max }$ of $0.42 \%, d_{33}^{*}$ of $840 \mathrm{pm} \mathrm{V}^{-1}$, and high $Q_{33}$ of $0.0404 \mathrm{~m}^{4} \mathrm{C}^{-2}$ (at RT) with a very high $Q_{33} / E\left(8.08 \times 10^{-9} \mathrm{~m}^{5} \mathrm{C}^{2} \mathrm{~V}^{-1}\right)$. The maximum 
energy storage density ( $W=0.65 \mathrm{~J} \mathrm{~cm}^{-3}$ @ $120{ }^{\circ} \mathrm{C}$ ) and energy storage efficiency $\left(\eta=90.4 \%\right.$ (a) $\left.120{ }^{\circ} \mathrm{C}\right)$ with large improvements are obtained for the $x=0.03$ ceramic. The studied results indicate that BFT enhances the electric field-induced strain, electrostrictive coefficient and energy storage density performances in BNKT-based ceramics. These ceramics can be considered promising candidates for actuator and high electric power pulse energy storage applications.

\section{Conflicts of interest}

There are no conflicts to declare.

\section{Acknowledgements}

This research work was supported by the Thailand Research Fund (TRF, BRG6080002) and partially supported by Chiang Mai University, Materials Science Research Center. Department of Physics and Materials Science, Faculty of Science, Science and Technology Research Institute, Chiang Mai University is also acknowledged.

\section{References}

1 Z. Jiang, R. Zhang, F. Li, L. Jin, N. Zhang, D. Wang and C. L. Jia, AIP Adv., 2016, 6, 065122.

2 J. Hao, W. Li, J. Zhai and H. Chen, Mater. Sci. Eng., R, 2019, 135, 1-57.

3 X. Liu, F. Li, J. Zhai, B. Shen, P. Li, Y. Zhang and B. Liu, Mater. Res. Bull., 2018, 97, 215-221.

4 W. Bai, L. Wang, P. Zheng, F. Wen, Y. Yuan, M. Ding, D. Chen, J. Zhai and Z. Ji, Ceram. Int., 2018, 44, 8628-8634.

5 W. Bai, D. Chen, P. Zheng, J. Zhang, B. Shen, J. Zhai and Z. Ji, Ceram. Int., 2017, 43, 3339-3345.

6 R. F. Ge, Z. H. Zhao, S. F. Duan, X. Y. Kang, Y. K. Lv, D. S. Yin and Y. Dai, J. Alloys Compd., 2017, 724, 1000-1006.

7 N. Zhao, H. Fan, X. Ren, S. Gao, J. Ma and Y. Shi, Ceram. Int., 2018, 44, 571-579.

8 F. Li, Y. Liu, Y. Lyu, Y. Qi, Z. Yu and C. Lu, Ceram. Int., 2017, 43, 106-110.

9 P. Jaita, A. Watcharapasorn, N. Kumar, S. Jiansirisomboon and D. P. Cann, J. Am. Ceram. Soc., 2016, 99, 1615-1624.

10 T. Zheng, J. Wu, D. Xiao and J. Zhu, Prog. Mater. Sci., 2018, 98, 552-624.

11 T. Takenaka, K. I. Maruyama and K. Sakata, Jpn. J. Appl. Phys., 1991, 30, 2236-2239.

12 W. Jo, J. E. Daniels, J. L. Jones, X. Tan, P. A. Thomas, D. Damjanovic and J. Rödel, J. Appl. Phys., 2011, 109, 014110.

13 S. Kim, H. Choi, S. Han, J. S. Park, M. H. Lee, T. K. Song, M. H. Kim, D. Do and W. J. Kim, J. Eur. Ceram. Soc., 2017, 37, 1379-1386.

14 X. Liu, S. Xue, J. Ma, J. Zhai, B. Shen, F. Wang, X. Zhao and H. Yan, J. Eur. Ceram. Soc., 2018, 38, 4631-4639.

15 A. Sasaki, T. Chiba, Y. Mamiya and E. O. Tsuki, Jpn. J. Appl. Phys., 1999, 38, 5564-5567.

16 Y. Hiruma, K. Yoshii, H. Nagata and T. Takenaka, J. Appl. Phys., 2008, 103, 084121.
17 A. Ullah, C. W. Ahn, R. A. Malik, J. S. Lee and I. W. Kim, J. Electroceram., 2014, 33, 187-194.

18 A. Ullah, A. Ullah, I. W. Kim, D. S. Lee, S. J. Jeong and C. W. Ahn, J. Am. Ceram. Soc., 2014, 97, 2471-2478.

19 S. T. Zhang, A. B. Kounga, W. Jo, C. Jamin, K. Seifert, T. Granzow, J. Rödel and D. Damjanovic, Adv. Mater., 2009, 21, 4716-4720.

20 J. Shi, H. Fan, X. Liu and A. J. Bell, J. Am. Ceram. Soc., 2014, 97, 848-853.

21 S. T. Zhang, A. B. Kounga, E. Aulbach, H. Ehrenberg and J. Rödel, Appl. Phys. Lett., 2007, 91, 112906.

22 Y. Hong, J. Li, W. Wu, Y. Wu, H. Bai, K. Shi, Q. Meng, Z. Zhou and D. Jia, Ceram. Int., 2018, 44, 16069-16075.

23 P. Jaita, P. Butnoi, R. Sanjoom, C. Randorn, R. Yimnirun and G. Rujijanagul, Ceram. Int., 2017, 43, S2-S9.

24 S. Manotham, S. Eitssayeam, K. Pengpat, T. Tunkasiri, D. Sweatman and G. Rujijanakul, Ferroelectrics, 2015, 487, 149-155.

25 F. Galasso, L. Katz and R. Ward, J. Am. Chem. Soc., 1959, 81, 820-823.

26 Z. Wang, X. M. Chen, L. Ni, Y. Y. Liu and X. Q. Liu, Appl. Phys. Lett., 2007, 90, 102905.

27 C. Kruea-In and G. Rujijanagul, J. Nanosci. Nanotechnol., 2017, 17, 8603-8607.

28 C. Kruea-In, S. Eitssayeam, K. Pengpat and G. Rujijanagul, Mater. Res. Bull., 2012, 47, 2859-2862.

29 R. D. Shannon, Acta Crystallogr., Sect. A: Cryst. Phys., Diffr., Theor. Gen. Crystallogr., 1976, 32, 751-767.

30 Z. W. Chen and J. Q. Hu, Adv. Appl. Ceram., 2008, 107, 222226.

31 R. A. Malik, A. Hussain, A. Zaman, A. Maqbool, J. U. Rahman, T. K. Song, W. J. Kim and M. H. Kim, RSC Adv., 2015, 5, 96953-96964.

32 P. Fan, Y. Zhang, B. Xie, Y. Zhu, W. Ma, C. Wang, B. Yang, J. Xu, J. Xiao and H. Zhang, Ceram. Int., 2018, 44, 3211-3217.

33 W. Bai, F. Liu, P. Li, B. Shen, J. Zhai and H. Chen, J. Eur. Ceram. Soc., 2015, 35, 3457-3466.

34 Y. K. Lv, S. F. Duan, Z. H. Zhao, X. Y. Kang, R. F. Ge, H. Wang and Y. Dai, J. Mater. Sci., 2018, 53, 8059-8066.

35 R. A. Malik, A. Hussain, A. Maqbool, A. Zaman, C. W. Ahn, J. U. Rahman, T. K. Song, W. J. Kim and M. H. Kim, J. Am. Ceram. Soc., 2015, 98, 3842-3848.

36 A. Maqbool, A. Hussain, R. A. Malik, J. U. Rahman, A. Zaman, T. K. Song, W. J. Kim and M. H. Kim, Mater. Sci. Eng., B, 2015, 199, 105-112.

37 A. A. Bokov and Z. G. Ye, Solid State Commun., 2000, 116, 105-108.

38 H. Xie, Y. Zhao, J. Xu, L. Yang, C. Zhou, H. Zhang, X. Zhang, W. Qiu and H. Wang, J. Alloys Compd., 2018, 743, 73-82.

39 X. Wei, Y. Feng, X. Wan and X. Yao, Ceram. Int., 2004, 30, 1397-1400.

40 G. Dong, H. Fan, J. Shi and Q. Li, J. Am. Ceram. Soc., 2018, 101, 3947-3955.

41 A. Hussain, C. W. Ahn, J. S. Lee, A. Ullah and I. W. Kim, Sens. Actuators, A, 2010, 158, 84-89.

42 X. Liu and X. Tan, J. Appl. Phys., 2016, 120, 034102. 
43 A. Ullah, R. A. Malik, A. Ullah, D. S. Lee, S. J. Jeong, J. S. Lee, I. W. Kim and C. W. Ahn, J. Eur. Ceram. Soc., 2014, 34, 29-35. 44 A. Ullah, C. W. Ahn, S. Y. Lee, J. S. Kim and I. W. Kim, Ceram. Int., 2012, 38S, S363-S368.

45 X. Liu and X. Tan, Adv. Mater., 2016, 28, 574-578.

46 K. T. Lee, J. S. Park, J. H. Cho, Y. H. Jeong, J. H. Paik and J. S. Yun, Ceram. Int., 2015, 41, 10298-10303.

47 P. Jaita, A. Watcharapasorn, D. P. Cann and S. Jiansirisomboon, J. Alloys Compd., 2014, 596, 98-106.

48 Q. Yao, F. Wang, F. Xu, C. M. Leung, T. Wang, Y. Tang, X. Ye, Y. Xie, D. Sun and W. Shi, ACS Appl. Mater. Interfaces, 2015, 7, 5066-5075.

49 V. D. N. Tran, T. H. Dinh, H. S. Han, W. Jo and J. S. Lee, Ceram. Int., 2013, 39, S119-S124.

50 V. D. N. Tran, H. S. Han, C. H. Yoon, J. S. Lee, W. Jo and J. Rödel, Mater. Lett., 2011, 65, 2607-2609.

51 J. Kuwata, K. Uchino and S. Nomura, Jpn. J. Appl. Phys., 1980, 19, 2099-2103.

52 M. B. Rauls, W. Dong, J. E. Huber and C. S. Lynch, Acta Mater., 2011, 59, 2713-2722.

53 A. Ullah, H. B. Gul, A. Ullah, M. Sheeraz, J. S. Bae, W. Jo, C. W. Ahn, I. W. Kim and T. H. Kim, APL Mater., 2018, 6, 016104.

54 Y. Guo, M. Gu, H. Luo, Y. Liu and R. L. Withers, Phys. Rev. B, 2011, 83, 054118.

55 H. S. Han, W. Jo, J. K. Kang, C. W. Ahn, I. W. Kim, K. K. Ahn and J. S. Lee, J. Appl. Phys., 2013, 113, 154102.

56 J. Hao, Z. Xu, R. Chu, W. Li and J. Du, J. Mater. Sci., 2015, 50, 5328-5336.

57 S. T. Zhang, F. Yan, B. Yang and W. Cao, Appl. Phys. Lett., 2010, 97, 122901.

58 P. Butnoi, S. Manotham, P. Jaita, C. Randorn and G. Rujijanagul, J. Eur. Ceram. Soc., 2018, 38, 3822-3832.

59 H. Zhang, P. Xu, E. Patterson, J. Zang, S. Jiang and J. Rödel, J. Eur. Ceram. Soc., 2015, 35, 2501-2512.

60 J. Hao, Z. Xu, R. Chu, W. Li and J. Du, J. Alloys Compd., 2015, 647, 857-865.

61 T. H. Dinh, J. K. Kang, J. S. Lee, N. H. Khansur, J. Daniels, H. Y. Lee, F. Z. Yao, K. Wang, J. F. Li, H. S. Han and W. Jo, J. Eur. Ceram. Soc., 2016, 36, 3401-3407.

62 W. Krauss, D. Schütz, F. A. Mautner, A. Feteira and K. Reichmann, J. Eur. Ceram. Soc., 2010, 30, 1827-1832.
63 H. B. Lee, D. J. Heo, R. A. Malik, C. H. Yoon, H. S. Han and J. S. Lee, Ceram. Int., 2013, 39, S705-S708.

64 H. Shi, Y. Zhu, Y. Zhao, C. Liu, X. Ren, J. Hao and W. Li, J. Alloys Compd., 2018, 767, 666-674.

65 J. Hao, Z. Xu, R. Chu, S. Chu, W. Li, P. Fu, J. Du and C. Hu, Mater. Lett., 2017, 193, 138-141.

66 W. Bai, D. Chen, Y. Huang, P. Zheng, J. Zhong, M. Ding, Y. Yuan, B. Shen, J. Zhai and Z. Ji, Ceram. Int., 2016, 42, 7669-7680.

67 N. Chen, W. Yao, C. Liang, S. Xiao, J. Hao, Z. Xu and R. Chu, Ceram. Int., 2016, 42, 9660-9666.

68 R. A. Malik, A. Hussain, A. Maqbool, A. Zaman, T. K. Song, W. J. Kim and M. H. Kim, J. Alloys Compd., 2016, 682, 302310.

69 K. Wang, A. Hussain, W. Jo and J. Rödel, J. Am. Ceram. Soc., 2012, 95, 2241-2247.

70 Y. Zhao, J. Xu, L. Yang, C. Zhou, X. Lu, C. Yuan, Q. Li, G. Chen and H. Wang, J. Alloys Compd., 2016, 666, 209-216.

71 B. Hu, H. Fan, L. Ning, Y. Wen and C. Wang, Ceram. Int., 2018, 44, 15160-15166.

72 R. A. Malik, A. Hussain, M. Acosta, J. Daniels, H. S. Han, M. H. Kim and J. S. Lee, J. Eur. Ceram. Soc., 2018, 38, 2511-2519.

73 B. Wang, L. Luo, X. Jiang, W. Li and H. Chen, J. Alloys Compd., 2014, 585, 14-18.

74 Z. Liu, P. Ren, C. Long, X. Wang, Y. Wan and G. Zhao, J. Alloys Compd., 2017, 721, 538-544.

75 H. Yang, F. Yan, Y. Lin, T. Wang, F. Wang, Y. Wang, L. Guo, W. Tai and H. Wei, J. Eur. Ceram. Soc., 2017, 37, 3303-3311.

76 Q. Xu, H. Liu, Z. Song, X. Huang, A. Ullah, L. Zhang, J. Xie, H. Hao, M. Cao and Z. Yao, J. Mater. Sci.: Mater. Electron., 2016, 27, 322-329.

77 L. Luo, B. Wang, X. Jiang and W. Li, J. Mater. Sci., 2014, 49, 1659-1665.

78 H. Yang, F. Yan, Y. Lin, T. Wang, L. He and F. Wang, J. Alloys Compd., 2017, 710, 436-445.

79 Q. Xu, J. Xie, Z. He, L. Zhang, M. Cao, X. Huang, M. T. Lanagan, H. Hao, Z. Yao and H. Liu, J. Eur. Ceram. Soc., 2017, 37, 99-106.

80 Q. Li, Z. Yao, L. Ning, S. Gao, B. Hu, G. Dong and H. Fan, Ceram. Int., 2018, 44, 2782-2788.

81 Q. Xu, M. T. Lanagan, X. Huang, J. Xie, L. Zhang, H. Hao and H. Liu, Ceram. Int., 2016, 42, 9728-9736. 